Original Research

\title{
The Lived Experience of Canadian University Students with Type 1 Diabetes Mellitus
}

\author{
Stephanie Hill BASc, RD*, Jacqui Gingras PhD, RD, Enza Gucciardi PhD \\ School of Nutrition, Ryerson University, Toronto, Ontario, Canada
}

\section{A R T I C L E I N F O}

\section{Article history:}

Received 16 August 2012

Received in revised form

28 March 2013

Accepted 23 April 2013

\section{Keywords:}

lived experience

type 1 diabetes

type 1 diabetes mellitus

university students

\begin{abstract}
A B S T R A C T
Objective: The purpose of this study was to examine the lived experiences of university students with type 1 diabetes mellitus.

Methods: University students participated in a 2-part focus group. Transcripts were analyzed thematically using an open-coding approach. Data analysis was guided by a framework analysis method and emergent themes were triangulated between study authors for validity.

Results: Three major themes identified in this study were food issues within the university environment, lack of diabetes awareness on campus and internal struggles related to the participants' relationships with their diabetes.

Conclusions: Results illustrate some of the unique challenges that interfere with diabetes selfmanagement, academic performance and quality of life among this sample of university students. Findings can provide insight for diabetes educators and other healthcare practitioners regarding the issues that may interfere with optimal diabetes self-care in this population. Findings also can be used to inform university administrators how to make the university environment more diabetes friendly for its students.
\end{abstract}

(C) 2013 Canadian Diabetes Association Open access under CC BY-NC-ND license.

\section{R É S U M É}

Objectif : Le but de cette étude était d'examiner les expériences vécues par les étudiants ayant le diabète sucré de type 1.

Méthodes : Les étudiants ont participé à un groupe de discussion en 2 parties. Les transcriptions ont été analysées de façon thématique au moyen d'une approche à codage ouvert (open-coding). L'analyse des données a été guidée par la méthode de l'analyse du cadre et les thèmes émergents ont été triangulés avec les auteurs de l'étude pour en déterminer la validité.

Résultats : Les 3 thèmes majeurs qui ont été relevés dans cette étude étaient les enjeux alimentaires de l'environnement universitaire, le manque de sensibilisation au diabète sur le campus et les luttes internes liés aux rapports qu'entretiennent les participants quant à leur diabète.

Conclusions : Les résultats illustrent certains des enjeux particuliers qui interfèrent dans la prise en charge autonome du diabète, la performance scolaire et la qualité de vie de cet échantillon d'étudiants. Les conclusions peuvent donner un aperçu aux éducateurs spécialisés en diabète et aux autres praticiens en soins de santé en matière d'enjeux pouvant interférer dans la prise en charge autonome optimale du diabète dans cette population. Les conclusions peuvent également être utilisées pour informer les administrateurs d'université sur la manière de rendre l'environnement universitaire plus respectueux de la santé des étudiants diabétiques.

(C) 2013 Canadian Diabetes Association Open access under CC BY-NC-ND license.

\footnotetext{
* Address for correspondence: Stephanie Hill, BASc, RD, School of Nutrition, Ryerson University, Kerr Hall South Room 349, 350 Victoria Street, Toronto, Ontario, Canada, M5B 2K3.

E-mail address: s3hill@gmail.com.
}

\section{Introduction}

Type 1 diabetes mellitus is a chronic condition that commonly develops in younger individuals and is defined as the primary result of pancreatic beta cell destruction (1), which ultimately results in a lack of insulin production in the body. Current therapy for this condition involves intensive management of blood glucose levels, which includes a rigorous daily routine of insulin injections, blood 
glucose monitoring, and diet and lifestyle modifications (1). Although the recommended treatment for type 1 diabetes mellitus is complex, time consuming and costly, it is critical in reducing the onset and progression of diabetes-related ...complications, such... as blindness, kidney disease, neuropathy and cardiovascular diseases $(2,3)$. Living with and adhering to the complex treatment regimen for type 1 diabetes mellitus often can interfere with various social, emotional and economic lifestyle choices (4,5), which consequently can diminish quality of life. Those patients who have the most trouble managing type 1 diabetes mellitus are adolescents and young adults (6-11). University students are of particular concern because the demands of student life on top of the stressors of living with diabetes put these individuals at greater risk of poor self-management $(4,5,12-16)$.

Certain elements of university life have been identified in the research literature as barriers or challenges to achieving appropriate diabetes self-management in this population. These include the following: (1) social issues, such as peer pressure, alcohol consumption $(6,10)$, smoking, drug abuse (4,6,17-20), dietary constraints $(4,5,15)$ and eating disorders $(6)$; (2) academic barriers, such as irregular schedules and routines, lack of time and financial issues (4,5,19); and (3) emotional and psychological barriers, such as stress (5), insufficient or lack of social support $(5,21)$, loss of parental involvement $(4,17)$, denial and rebellion toward diabetes self-management (5), and emotions of anger, frustration and sadness as a result of feeling isolated from peers (22).

Research to date suggests that the unpredictable nature of type 1 diabetes mellitus can be challenging, especially for young adults who face the stressful demands and routines of university life (4,5,12-16). Given the lack of Canadian data in the current body of literature, the objective of this study was to explore the lived experiences of university students with type 1 diabetes mellitus in a Canadian university to better understand the challenges of living and coping with type 1 diabetes mellitus at this life stage. This study also aimed to identify pertinent issues that may assist practitioners who provide care in similar environments and university administrators on how to make the university environment more diabetes friendly for its students.

\section{Methods}

Phenomenology informed the methodology for this study. The phenomenologic nature of this study's qualitative inquiry led us to focus on understanding the participants lived experiences rather than the ability to generalize the data. Mosselson (23) argued that this type of experiential research allows the researcher to gain a deeper understanding of the phenomenon (university students living with type 1 diabetes mellitus) being explored. A 2-part focus group was used to collect data. The use of focus groups to obtain data helped capture a full spectrum of thoughts and experiences to better understand participants' lived experiences through their own understandings. Rabiee (24) described the strength of focus groups as providing a way to understand the meanings, beliefs and cultures that influence individuals' feelings, attitudes and behaviours.

Ten questions were asked in the focus group sessions. Questions were based on a prior literature review, and were open ended and broad in nature to provoke participants to discuss a range of experiences (Table 1). Each question was discussed until all participants had contributed their relevant thoughts and experiences. Each focus group session was audiotaped and lasted between 1.5 and 2 hours.

Upon receipt of approval from the university-affiliated research ethics board, students were recruited for the study within 1 university in the city of Toronto. Students who were part of a preexisting support group for university students with type 1
Table 1

Focus group questions

First session

1. Describe your overall experience living with and managing your diabetes since you have been at university?

2. What would you say are your difficulties with having diabetes in university?

3. So now we are going to talk about managing your diabetes, and specifically your ability to do what you think is optimal (whether you do it or not) for good management. Overall, how well do you feel/think you are able to manage your diabetes (in your definition of what is optimal management) considering the situations that university presents?

4. Are there any particular experiences, not including the ones we already have discussed, that you can remember while in any university scenario during which you felt disadvantaged or even discriminated against because you have type 1 diabetes?

Second session

5. Since our last focus group, I am sure that you all have been thinking of what we talked about, so I want to start by asking you if there was anything that you did not get to mention last time, or that you thought of afterward that you wanted to mention.

6. Thinking about why you came to university and the goals and objectives that you have for yourself here, in what ways do you feel diabetes and diabetes self-care affect those goals and objectives? This can be in both positive and negative ways.

7. Stress is a big factor that affects diabetes management. Take a moment to think about how you manage the stress in your current student life; this behaviour can be positive or negative. Now, in what ways do you cope with the stresses of university life, and do you think your coping mechanisms positively or negatively affect your diabetes management? Just before anyone answers, I want to say that because this is a very personal question, please remember no one here is being judged by anyone and we all respect one another's contributions.

8. By a show of hands, how many people in the room had diabetes before starting university? This question is directed to those people: since attending university do you feel your diabetes self-management has changed or been affected in any significant way?

9. How has the university helped or hindered your ability to care for your diabetes?

10. What programs/policies/initiatives, if any, would you like to see in place in a university setting to help you to manage, cope and enjoy student life living with type 1 diabetes?

diabetes mellitus were contacted via e-mail; others were reached through university-wide advertising by the use of posters. Contacting students who were part of the support group was performed to optimize recruitment through directly reaching the target population. Recruitment from both the pre-existing support group and the general student population on campus was important because these 2 groups may have different experiences living with type 1 diabetes mellitus on campus. All participants had to have type 1 diabetes mellitus, be a university student within the past 2 years at the time of data collection and be older than 18 years of age.

A total of 9 students, 3 males and 6 females, participated in the focus groups. Six participants ( 3 males and 3 females) attended both consecutive focus group sessions. Three other female participants attended only 1 of the sessions, with 2 of these participants taking part in the first session and 1 participant taking part in the second session. Six of the students recruited also attended the diabetes support group on campus. Participants' year of study ranged from their first to fourth year within undergraduate programs; 1 participant was a doctoral student. All of the students were in different programs of study. Four of the students lived away from home, and 5 lived at home. The students had been living with diabetes from 6 to 22 years, and all of them had diabetes before beginning postsecondary education. Participants were given a Can $\$ 20$ honorarium for each session attended, as well as dinner during the session. Informed consent was obtained from all recruited participants in this study.

All audio data were transcribed verbatim on completion of the focus group sessions. Transcripts were analyzed thematically using 
an open-coding approach. The analysis followed the Framework Analysis method described by Ritchie and Spencer in Rabiee (24). This method involves a systematic progression through the following interconnected stages: familiarization, identification of a thematic framework, indexing, charting, mapping and interpretation (24). To increase study validity, all study authors reviewed and interpreted the transcripts independently, after which their interpretations were compared for similarities and differences. These in-depth team discussions lead to the interpretations as reported.

\section{Positioning researchers in qualitative inquiry}

At the time of the study Stephanie Hill was an undergraduate nutrition student whose own experience with type 1 diabetes was a motivating factor in conducting this research. Dr. Gucciardi is an academic researcher whose area of research is in diabetes selfmanagement. Dr. Gingras is a registered dietitian and an academic researcher with special expertise in qualitative research methods. Stephanie Hill facilitated both of the focus groups. Although she had no previous experience conducting focus groups, both Dr. Gucciardi and Dr. Gingras trained and supervised Stephanie Hill. It was decided that Stephanie Hill would facilitate the focus groups because the participants would be more likely to see someone with diabetes as an equal and likely would feel more comfortable sharing information. She was also the coordinator of the student support group; however, when students were contacted about the study they were all advised that participation in the study would not affect their involvement in the support group. Assumptions of all the researchers were that the students likely faced challenges related to their diabetes similar to what other studies have reported. Because of the primary researcher's personal experience with diabetes, her assumptions were more specific in regards to what those challenges might be, however, these assumptions were confirmed in the literature. Despite the similarity of the researchers' assumptions and the literature, the researchers were not convinced that the experiences for Canadian students would be identical to student populations from other countries. To help minimize the potential influence of bias in the study, all study authors reviewed and interpreted the transcripts independently, as described in the methods section.

\section{Results}

Three major themes were identified in this study and are outlined later.

\section{Food issues within the university environment}

Eating healthful foods was important for all the participants because they perceived it to have a great impact on their ability to manage their diabetes. As a result, eating and accessing food within the university environment was a major concern. The students identified 2 specific issues as important: the types of foods offered and where food/eating food was permitted on campus.

The lack of healthful food options in the university cafeterias left the students feeling distressed about their inability to eat well while on campus. "I find that a lot of the food that I get from the cafeteria is high fat and not healthy, because I really try to aim for healthy foods because of my health. I find that is very difficult." Students desired healthier alternatives to meet their specific nutrition needs, such as a wider variety of sugar-free products and meal options that contained appropriate amounts of carbohydrates as opposed to offering too much or too little. In addition, the lack of nutrition-related information about the foods offered in the cafeteria created challenges in self-managing their diabetes. Specifically, students described how this information would be helpful for estimating insulin doses as well as knowing which items were more appropriate in terms of carbohydrate quantity. "And it's very hard to carb count... like I never get pasta here because I don't know how many cups of pasta there are in a serving." These issues were less burdensome for students who lived at home because they did not have to rely on campus food for all their meals.

The students also were concerned about the areas on campus where food was prohibited, such as in the library, examination rooms and laboratories. Their main worry was related to their fear of hypoglycemia. "There is no food allowed in the lab or studio under any circumstances, and if I leave [to get food] I won't be able to catch the lecture." When discussing the flexibility of these rules for special circumstances, such as having diabetes, the students' opinions differed. Some students understood that it was easy enough to get around those rules by discussing the issue with their instructors. "I had a quiz, and then I literally told my professor that I had diabetes and that I need fast-acting sugar with me and she understood. I think that we really need to bring up our diabetes in those situations, to let them know what we need." Other students felt uncomfortable addressing this issue with their instructors because of fears of being singled out or being different from their peers. In general, the consensus was that the students felt that the special circumstances that may override the rules, such as having diabetes, should be made more explicit by the instructors or university administrators. "Everyone wants food in [the classroom] too, however not for the same reasons...and I'm sure that they would bend the rules, but they need to make it clear that those rules are bendable."

\section{Lack of diabetes awareness on campus}

Lack of awareness about type 1 diabetes mellitus among their university peers and instructors was a great concern for students. Issues discussed in the focus group included misconceptions about the cause of diabetes as being related to obesity, stereotypes about people with diabetes and misunderstanding of diabetes management practices among their peers. Lack of awareness in the university environment was also a large source of stress and frustration for students because they constantly needed to explain themselves in relation to their diabetes. This frustration sometimes resulted in choosing to neglect their diabetes management in various ways, such as not testing their blood sugar, postponing or omitting insulin injections, and engaging in other risky behaviours. "I'm just tired of explaining what I'm doing...these people don't even care...It's like get over it, I'm over it...So it leads me to not whip out my blood sugar monitor...That is a negative experience."

Lack of awareness about the medical implications of diabetes in the university environment was also a significant challenge for students. Many of them recalled having had extensive support networks in high school in which instructors and peers were aware of their condition and the necessary precautions. Students described feeling insecure in the university environment, especially with regard to severe episodes of hypoglycemia in which they may need assistance. They felt that neither resources nor people with sufficient knowledge would be available to help them. One participant stated, "when you are in high school...everyone around you knows that [participant's name] is a diabetic, she's acting funny, like maybe we should check up on her, whereas here, no one knows and how would they? Like they wouldn't know to ask." Another participant stated, "in a huge class...they might not be qualified to know what to do. I've had people that say, 'you're diabetic, oh you can't eat sugar whatsoever.' So it doesn't matter if I wear a medic alert bracelet, because they are just going to think I need insulin, and that would more or less kill me."

Findings further reveal that the students felt especially uncomfortable and vulnerable in the classroom, which was not 
considered a diabetes-friendly environment. Some of the students felt embarrassed about their diabetes, particularly when they had to perform diabetes self-management practices in class, such as testing their blood glucose or treating hypoglycemia. "I'm embarrassed when I get a low (referring to low blood glucose) to the point where I can't even walk...I'm afraid to get up in front of class to leave, and so if I run out of juice, like, what am I supposed to do?" The students explained that these feelings of embarrassment were the result of the lack of understanding and awareness about diabetes and management practices. "[I]f I pull out my pump, they think I'm texting someone and I'll get rude looks." "One time my pump beeped and this girl gave me a dirty look." In summary, the student's experience living with type 1 diabetes mellitus in the university environment was not as positive and supportive as their experience in grade school and high school. Although the students did not expect that the university would be run in the same manner, they still felt that these issues, if addressed, would improve their quality of life.

The fact that the university community was largely ignorant of type 1 diabetes mellitus was a problem further compounded by the fact that most people were not aware that these particular students had type 1 diabetes mellitus. Again, this situation was in contrast to their high school community where everyone was well aware of their condition. This foreign situation created some unique challenges for the students. They noted that it was easier to mismanage their diabetes because they did not have people around them to encourage appropriate management. "It's different from when you come from high school [where] you are a lot closer with a lot more people, and you come to university, you have friends, but you also are afforded the space to do your own thing, and that allows you to have the privacy to, um, not take care of yourself as well as you can." This also increased their fear related to the potential events of severe hypoglycemia because few people may have the knowledge necessary to help them. For students who lived away from home this was a greater concern because they had even less connection with people who are aware of their condition and their needs. The students explained that this new privacy encouraged them to allow their blood glucose level to be increased in an effort to prevent severe hypoglycemia. "I think that the isolation in university really drove me to keep my sugars higher. It's like a safety net." "I'm not afraid to go to sleep with my blood sugars at 12 , because my blood sugars drop a lot in the night." Although the students appeared to be able to cope with these changes in the university setting, being in an environment where few people were aware of their condition was an important hallmark of the university experience; it challenged them to become more independent in the management of their condition.

\section{Internal struggles: participants' relationships with their diabetes}

The third theme from the data was related to the apparent internal struggles the students faced regarding their relationship with their diabetes. The inner conflict showed an evolution in the students' relationship with diabetes. It was clear that as their identity changed to adapt to university life, their attitude and coping strategies for self-management changed as well, but this was not a transition without struggle.

\section{Private and public self with diabetes}

It was apparent during the focus group sessions that the students struggled with the issue of disclosing their diabetes to others. Willingness to disclose their condition depended on the students' comfort level and the reason for disclosure. The decision to keep their diabetes private was influenced by the potentially negative consequences of disclosure. For example, the students discussed the perception that others may have of their condition and the resulting assumptions that can be made regarding their ability. "When I was signing up [for the university gym], they gave me this weird survey....and they asked about medical conditions, and I felt obligated to lie about having diabetes... because I thought that they wouldn't let me into their stupid gym." The students also feared the implications of disclosure on their professional lives and careers. "[M]y goal was to work at sporting events and I was told by my professor that I should keep my diabetes a secret because I would never be hired, because they will worry that during a big game you'll pass out or something." Other reasons why students concealed their condition included not wanting pity from others, and to avoid being labelled or feeling different from their peers. Most students, however, generally felt comfortable disclosing their diabetes to peers, friends, instructors and university administration when their safety was a concern, such as the potential for unpredictable hypoglycemia.

\section{Disability and diabetes}

The second internal struggle for the students was the notion of diabetes as a disability, which was conceptualized in conflicting ways. In some instances, they resisted being labelled as disabled because of their diabetes, as was made evident when they were referred to disability services within the university for assistance with academic endeavors. "I feel like disability is someone who can't do something, and I have yet to encounter something that I can't do. It may be harder, but I can do whatever anyone else can...so I don't know if I would classify myself as disabled." "I never used the disability services. I was actually told by one professor to use it, and I refused outright because I wanted to do it on equal terms." In this regard, the students felt they were as competent as any other student and did not need any special privileges. On the other hand, the students also acknowledged they were disabled because their condition prevented them from experiencing life in the same way as those who do not have diabetes. Despite their struggle with the conceptualization of disability in the context of diabetes, the students wanted the university community to understand that diabetes is complex and has implications on their day-to-day lives, but also that they are resilient and can overcome the challenges diabetes presents. "I think we all want the university to be more understanding. It is not that I want their empathy...we are equal but we have special needs. Sometimes I want to take advantage of [disability services], however, I think that someone will look at me and say, “you are not disabled." But I don't want to take advantage, because I want to do it on equal terms. But what I want is the understanding, especially from our peers."

\section{Caring for diabetes and academic obligations}

The last struggle that emerged was related to finding a balance between caring for their health and meeting academic obligations. Many students noted the challenges inherent in concurrently managing their diabetes and completing academic tasks. Diabetes affected their ability to perform academically mainly because of the fatigue that resulted from hypoglycemia and hyperglycemia. "I think the greatest difficulty for me is concentrating in class. If my blood sugars aren't spot on, like if I'm low, I just feel so awful, for me, I just feel like I'm drunk. I can't do anything, I can't walk right or speak right, I'm just clumsy. So I don't want to go to class, and if I'm in class, I'll just leave. If my blood [glucose] is high, I'm tired, I can't concentrate, I feel like I'm going to fall asleep at the drop of a hat. So again, if my blood sugars aren't spot on, I tend to miss the class or just not go." Stress from their academic responsibilities also affected their ability to metabolically self-manage. Two students remarked on how their glycated hemoglobin (A1C) level has 
increased significantly since starting university, which they attributed to academic stress. Interestingly, some of the students reported forgoing some aspects of diabetes management to attain academic goals. For some students, this was very distressing because they understood the ramifications of neglecting their selfcare. For others, this was considered something they had to do at this stage in their life. "The more things that get put on the list, then the further down the list my diabetes gets put. Especially in my program, a degree won't matter if I don't have a good portfolio. So those things take priority, because I'm going to be a diabetic for the rest of my life, and I only have a small window of time to get my foot in the door to start my career."

\section{Discussion}

The findings suggest that hypoglycemia was of great concern for this population. Students expressed their frequent fear of experiencing a severe hypoglycemic episode, especially with the restriction on bringing food into classrooms, and the lack of trusted, knowledgeable persons available to care for them during an episode. Students appeared to have a good understanding of how to deal with a possible hypoglycemic episode (e.g. disclosing their condition to close friends, carrying extra fast-acting carbohydrates to treat hypoglycemia); however, they still worried about and feared these situations. This fear affected their ability to concentrate and be fully engaged in their academic studies.

Wdowik et al (5) found that fear of hypoglycemia was an important barrier in the management of type 1 diabetes mellitus in university students and stressed the importance of social supports in the day-to-day management of diabetes. The most common form of support was a friend, roommate or significant other who readily was available to assist in hypoglycemia emergencies (5). Wdowik et al (5) also found that many students rarely tested their blood sugars and that this contributed to the high frequency of hypoglycemia (5). Although the embarrassment of blood glucose monitoring in public was discussed by our participants, the actual frequency of testing was not. It may be reasonable to suppose that embarrassment led to less frequent testing as well. Therefore, more testing may help to reduce the fears of hypoglycemia that often distract students from their academic responsibilities. This is not to say that testing will eliminate fears of hypoglycemia completely, but rather to suggest that testing may help reduce fears to allow students to focus on their tasks at hand, academic or otherwise. Students' concerns regarding hypoglycemia also were related to the recurring issue of food being prohibited in areas throughout the university. Although some students understood the need to plan ahead and make their special needs known to the appropriate people in regards to food (e.g. explaining to professors that they need to have fast-acting carbohydrates with them during class and examinations), it was clear that some students struggled with addressing this issue.

According to the results of this study, efforts to assist students with hypoglycemia-related fears should focus on educating them on the benefits of regular glucose testing regimens, strategies to prevent the occurrence of hypoglycemia, and using peer-support strategies such as a diabetes buddy program or encouraging students to connect with someone who would be able to assist in hypoglycemia emergencies in their residence and in the classroom. In the literature, diabetes education programs specifically designed for university students have been shown to improve self-care behaviours, diabetes knowledge, feelings of support $(12,13)$ and A1C levels $(13,21)$. At the university level, policies that are more responsive to the needs of students with type 1 diabetes mellitus also may help improve quality of life through reducing fear of hypoglycemia, for example, policies that protect students' right to have medical supplies and food with them during examinations and in libraries and laboratory settings, without being segregated from the rest of the student body.

There are obvious internal tensions between the life of a university student and the life of a young adult living with diabetes: the former allows more autonomy and experimentation, and the latter requires more discipline (16). The internal struggles discussed in this study show some of these tensions, that is, how the participants were in constant flux between living a normal student life and having and managing diabetes. Furthermore, students' attempts to be normal may have deleterious effects on their diabetes management (16). For example, university students living with diabetes in our study strived to be normal by keeping their diabetes private, neglecting self-management practices in public, rejecting extra support or resources to avoid being labelled as disabled, and aiming to perform on par academically with their peers even at the expense of diabetes self-care. Healthcare providers or support counselors may be able to provide assistance to this population through identifying coping strategies to better balance diabetes self-care and university responsibilities and lifestyles.

Study findings further show a need to develop and provide social support services to university students living with type 1 diabetes mellitus. The participants faced various challenges in the university environment, from integrating their identity as university students living with diabetes, to the lack of awareness and support within the university environment. As confirmed by our participants, university students with type 1 diabetes mellitus find it more difficult to manage their condition in the university environment than in high school settings (4). All participants agreed that they would find it helpful to see more support services for diabetes in the university environment. They expressed a strong desire to meet and talk to other students with diabetes. In a similar study, half of the college students participating wanted more social supports and to interact with other peers living with diabetes (5). Support services that may benefit university students living with diabetes include the following: peer-support groups, diabetes buddy programs to pair interested students with diabetes together to facilitate a support network, and diabetes self-management education provided on campus for students. Given the poor glycemic control reported among university or college students with type 1 diabetes mellitus owing to physical, social and emotional concerns (4), such interventions also are likely to improve selfmanagement, academic success, student retention and student engagement within this population.

One primary issue affecting the students' level of perceived support was the fact that university staff generally were unaware that the students required accommodation as a result of their condition. This lack of awareness was emotionally difficult for the students to deal with, and was perceived as dangerous to their health and the management of their condition. The underlying frustration appeared to be caused by the fact that although assistance in a crisis, mainly hypoglycemia, was very simple (e.g. provide glucose), it was not widely known. Much work in policy development and research has established where responsibilities lie for the day-to-day management of elementary school students with diabetes (25-27). A great emphasis is placed on the need for authority figures to be aware of students' medical conditions and the accommodations they require in these settings (25). Because of the much larger student population in universities, mirroring the elementary system may not be logistically feasible; however, there may be something to learn from the effectiveness of these systems. The students in this study clearly had felt more secure in their elementary and high school environments, and the main reason was because their teachers and the school administration were aware of their condition and appeared to care about it. Future research should examine alternate ways to create safe 
environments for university students with type 1 diabetes mellitus to decrease their fears of hypoglycemic events.

A major limitation of this study was the small sample size. The original intention was to have at least 12 students in each focus group session. The inability to recruit the desired number of participants may have resulted from the short recruitment time period of only 1 month, as well as the timing, which was at the beginning of a school semester. Given the hectic nature of the start of the academic year, this may have been a suboptimal time for recruitment. Future studies should plan a strategic recruitment that takes into account common student routines/schedules to ensure an adequate sample size. To improve recruitment, future research should consider a methodology that is not time intensive and is flexible with regard to accommodating participants' schedules. Generalizability of our study results may be limited because the majority of participants also participated in the student support group, which may indicate that this study sample reflects the opinions of students who have and want support and not other students who do not desire or need support. Despite the limitations discussed, strengths of the study design included using phenomenology to inform the methodology and focus groups as a method of data collection to gain a thorough understanding of the complex issues involved in the lived experiences of our participants. Use of the primary researcher to facilitate the focus groups may be seen as a strength because of the primary researcher's personal experience with diabetes. Mosselson (23) argued that the positionality of the researcher can be made visible in the research process to not only enhance the ethical integrity of the research, but also to enhance both the veracity of the research process and the analysis and interpretation of the data. Finally, the independent review and interpretation of the transcripts by all researchers improved the validity of the study results.

\section{Conclusion}

Our research findings contribute to the literature by enhancing the understanding of the challenges that university students with type 1 diabetes mellitus face in an urban Canadian university. Results illustrate some of the unique challenges present for this population when on campus, which include hypoglycemia fears, lack of support and awareness regarding diabetes, and food issues. These challenges interfered with diabetes self-management, academic performance and quality of life among this sample of university students. Because the majority of the participants were recruited from the existing support group, the results of this research may limit generalizability. However, this should not discount the valuable information revealed through understanding the experience lived by this group of participants. It is hoped that this research can act as a catalyst to encourage more in-depth research in this population and changes regarding university support and university policy in Canadian universities to address the concerns as explained through our participants' understanding of them. Specifically, findings can provide insight for healthcare practitioners and academic counsellors regarding optimal diabetes self-care and academic success in this population. Findings also can be used to inform university administrators on how to make the university environment more diabetes friendly for its students. Further research is necessary to develop and evaluate initiatives to create diabetes friendly environments for university students with type 1 diabetes mellitus. To support the success of such initiatives, it is paramount that university policies are modified simultaneously. A multidisciplinary approach to such research and policy development would best reflect the range of needs in this population.

\section{References}

1. Canadian Diabetes Association. 2008 Clinical Practice Guidelines for the Prevention and Management of Diabetes in Canada. Can J Diabetes 2008; 32(suppl 1):S10.

2. Diabetes Control and Complications Trial Research Group. Effect of intensive diabetes treatment on the development and progression of long-term complications in adolescents with insulin-dependent diabetes mellitus: diabetes control and complications trial. J Pediatr 1994;125:177-88.

3. Nathan DM, Cleary PA, Backlund JY, et al. Intensive diabetes treatment and cardiovascular disease in patients with type 1 diabetes. N Engl J Med 2005;353 2643-53.

4. Ramchandani N, Cantey-Kiser JM, Alter CA, et al. Self-reported factors that affect glycemic control in college students with type 1 diabetes. Diabetes Educ 2000;26:656-66.

5. Wdowik MJ, Kendall PA, Harris MA. College students with diabetes: using focus groups and interviews to determine psychosocial issues and barriers to control. Diabetes Educ 1997;23:558-62.

6. Bryden KS, Peveler RC, Stein A, et al. Clinical and psychological course of diabetes from adolescence to young adulthood: a longitudinal cohort study. Diabetes Care 2001;24:1536-40.

7. Maclean HM. Patterns of diet related self-care in diabetes. Soc Sci Med 1991; 32:689-96

8. Maharaj SI, Rodin GM, Olmsted MP, et al. Eating disturbances in girls with diabetes: the contribution of adolescent self-concept, maternal weight and shape concerns and mother-daughter relationships. Psychol Med 2003;33: 525-39.

9. Wolpert HA, Anderson BJ. Young adults with diabetes: need for a new treatment paradigm. Diabetes Care 2001;24:1513-4.

10. Balfe M. The body projects of university students with type 1 diabetes. Qual Health Res 2009;19:128-39.

11. Morris AD, Boyle DI, McMahon AD, et al. Adherence to insulin treatment, glycaemic control, and ketoacidosis in insulin-dependent diabetes mellitus. The DARTS/MEMO collaboration. Diabetes audit and research in Tayside Scotland. Medicines monitoring unit. Lancet 1997;350:1505-10.

12. Wdowik MJ, Kendall PA, Harris MA, et al. Development and evaluation of an intervention program: "control on campus". Diabetes Educ 2000;26:95-104.

13. Clapham L, Mitchell C, Flatley C, et al. Providing diabetes care and support to students in higher education. J Diabetes Nurs 2008;12:187.

14. Wdowik MJ, Kendall PA, Harris MA, et al. Expanded health belief model predicts diabetes self-management in college students. J Nutr Educ 2001;33:17-23.

15. Balfe M. Diets and discipline: the narratives of practice of university students with type 1 diabetes. Sociol Health Illn 2007;29:136-53.

16. Eaton S, Williams R, Bodansky HJ. Diabet Med18. University students with diabetes; 2001. p. 940-2.

17. Strachan MW, MacCuish AC, Frier BM. The care of students with insulin-treated diabetes mellitus living in university accommodation: scope for improvement? Diabet Med 2000; $17: 70-3$.

18. Miller-Hagan RS, Janas BG. Drinking perceptions and management strategies of college students with diabetes. Diabetes Educ 2002;28:233-44.

19. Mellinger DC. Preparing students with diabetes for life at college. Diabetes Care 2003;26:2675-8.

20. Bryden KS, Dunger DB, Mayou RA, et al. Poor prognosis of young adults with type 1 diabetes: a longitudinal study. Diabetes Care 2003;26:1052-7.

21. Geddes J, McGeough E, Frier BM. Young adults with type 1 diabetes in tertiary education: do students receive adequate specialist care? Diabet Med 2006;23: 1155-7.

22. Shalom R. A pilot study of support and education groups for college students with insulin-dependent diabetes mellitus. J Am Coll Health 1991;39:277-9.

23. Mosselson J. Subjectivity and reflexivity: locating the self in research on dislocation. Int J Qual Studies Educ 2010;23:479-94.

24. Rabiee F. Focus-group interview and data analysis. Proc Nutr Soc 2004;63: 655-60.

25. National Asthma Education and Prevention Program-School Subcommittee, National School Boards Association, American School Health Association, et al. Students with chronic illnesses: guidance for families, schools, and students. J Sch Health 2003;73:131-2.

26. American Diabetes Association. Care of children with diabetes in the schoo and day care setting. Diabetes Care 2002;25(Suppl 1):S122-6.

27. Mandali SL, Gordon TA. Management of type 1 diabetes in schools: whose responsibility? J Sch Health 2009;79:599-601. 